\title{
DA CRISE À ABUNDÂNCIA: \\ Segurança alimentar e modernização agrícola na Europa no pós-Segunda Guerra Mundial
}

\section{FROM CRISIS TO ABUNDANCE: Food security and agricultural modernization in the post-World War II Europe}

Patrícia Nasser de Carvalho*

\begin{abstract}
RESUMO: O objetivo deste artigo é relacionar a crise alimentar e humanitária vivida pela Europa no pós-Segunda Guerra às ações dos Estados europeus para superá-la e para garantir sua segurança alimentar. O conflito foi determinante para a decisão das nações europeias de proteger e estimular a modernização do campo por meio de políticas públicas. A partir da década de 1950, os processos de produção e de distribuição de bens agrícolas entraram em uma nova fase de mudanças estruturais em muitos países europeus, tendo em vista que as unidades agrícolas foram se tornando empresas altamente produtivas.
\end{abstract}

PALAVRAS-CHAVE: Europa. Segunda Guerra Mundial. Crise alimentar.

\begin{abstract}
The aim of this article is to relate the post-World War II food and humanitarian crisis to the actions of European states to overcome it and to ensure their food security. The conflict was decisive for the decision of the European nations to protect and stimulate the modernization of the countryside through public policies. From the 1950s the processes of production and distribution of agricultural goods entered a new phase of structural changes in many European countries, as agricultural units became highly productive enterprises.
\end{abstract}

KEYWORDS: Europe. World War II. Food crisis.

\section{Introdução}

A Segunda Guerra Mundial teve extraordinário impacto sobre o setor agrícola e alimentar da Europa. Destruição da infraestrutura, obstrução das vias de comunicação, grande mobilização das terras produtivas e da força de trabalho do campo no suporte às forças armadas, além de invasões, bloqueios militares, saques, pilhagens e contrabando resultaram, ao final do conflito, na falta de alimentos, de bens de consumo de primeira necessidade e de energia na maioria dos países europeus. Em vista disso, a fome se manifestou como um dos mais graves problemas durante e após o fim do confronto e contribuiu para manter a sensação de insegurança que permeava o continente europeu desde a Primeira Guerra Mundial.

A privação de alimentos básicos, que atingiu milhões de pessoas, implicou em ações emergenciais por parte dos governos da Europa ainda durante o confronto. Além da imposição de regulações para a distribuição de alimentos segundo categorias, após o cessar-fogo, em 1945, as lideranças políticas agiram no sentido de apoiar e proteger a recuperação da agricultura a partir da formulação de programas de investimentos e de

\footnotetext{
* Professora Adjunta do Departamento de Ciências Econômicas da Universidade Federal de Minas Gerais (UFMG). Doutora em Economia Política Internacional pela Universidade Federal do Rio de Janeiro (UFRJ).
} 
outras formas de intervenção setorial por parte do Estado a fim de ampliar a produção de bens agroalimentares. $\mathrm{Na}$ concepção desses líderes, sua nação deveria se tornar soberana na produção dos bens considerados essenciais à dieta alimentar local. Do contrário, se os tivessem que continuar importando em grande quantidade, permaneceriam não só muito dependentes da provisão externa, o que colocaria os mercados nacionais em uma posição estrategicamente desfavorável, senão também bastante suscetíveis às flutuações de preços no mercado internacional (ZOBBE, 2011). Para agravar essa situação, por volta de 19461947, novos enfrentamentos voltaram a ser uma ameaça para a região com o início da Guerra Fria. A Europa, novamente, parecia ser o palco mais provável deles (MILWARD, 1980).

Além do caráter estratégico da agricultura, no discurso das autoridades políticas das nações europeias, as terríveis experiências históricas de confrontos e suas consequências foram fortes razões para que os governos sustentassem políticas de interferência do Estado no setor agrícola nas décadas posteriores à Segunda Guerra Mundial. Ademais das incertezas relativas aos preços agrícolas - normalmente vistos como mais voláteis no mercado interancional do que dos demais bens -, a necessidade de defender o bem-estar dos cidadãos e a necessidade de defender a propriedade familiar - esta última tradicionalmente admitida pela maior parte da população europeia como um símbolo histórico da sociedade e responsável pela produção de bens vitais - foram os principais motivos que legitimaram o apoio direto dos Estados à produção agroalimentar na maioria dos países europeus. Nas décadas seguintes, essas razões foram mantidas como motivações dos governos europeus para continuar justificando sua interferência no setor. Portanto, a partir do esforço concentrado dos Estados europeus em apoiar a agricultura com investimentos em práticas intensivas em tecnologia, educação e infraestrutura, iniciados a partir da segunda metade dos anos 1940, em pouco tempo, eles saíram da condição de insuficiência alimentar e alcançaram a restauração completa de seus padrões de produção e de consumo. Os processos produtivos e de distribuição de bens agrícolas entraram em uma fase de mudanças estruturais, que alavancaram a produtividade do campo e transformaram as formas de produção e de consumo em muitos países da Europa, sobretudo da parte ocidental do continente (FRIEDMANN; McMICHAEL, 1989). Desse modo, eles deixaram de se voltar essencialmente a garantir o suprimento alimentar básico do seu mercado doméstico e visaram apoiar a acumulação de capital dos grandes proprietários rurais, tendo em vista que as unidades agrícolas foram se tornando empresas altamente produtivas de gestão eficiente (FRIEDMANN, 1995).

O objetivo deste artigo é relacionar a crise alimentar e humanitária vivida pela Europa no pós-Segunda Guerra às ações dos Estados europeus para superá-la. Verifica-se que o último grande conflito mundial foi um evento determinante para a sua decisão de proteger e estimular a modernização do campo e dos seus mercados agrícolas, a fim de garantir a segurança alimentar dos Estados por eles liderados. Com os traumas e os efeitos perturbadores, e, ao mesmo tempo, com a certeza de que a situação de precariedade poderia ameaçar a estabilidade social e a soberania de cada Estado-nação, os líderes da Europa, cujos mercados eram dependentes das importações de bens agroalimentares e de insumos para a geração de energia, conferiram sentido de urgência à suplantação desse quadro a partir de soluções primordialmente públicas.

Por meio de uma pesquisa histórica e explicativa, verifica-se que o processo de modernização do campo possibilitou que muitos países europeus saíssem da situação de escassez e alcançassem a abundância na produção de bens agroalimentares nos anos 1950, tornando-o, em pouco tempo, um setor agrícola muito protecionista, e o convertendo em um domínio gradativamente mais produtivo. Foram conferidas condições ideais de produção às empresas agrícolas. Esse modelo se consolidou em muitos países da Europa Ocidental a partir do imediato fim da Segunda Guerra Mundial e pouco tempo depois passou a funcionar não mais segundo a lógica assistencialista, isto é, aquela voltada a ações estruturadas priorizando a assistência social, mas segundo a racionalidade da produção máxima e eficiente, enquadrando os mercados agrícolas europeus nos novos padrões de 
produção, especialização, consumo e comércio globais sob o regime alimentar mercantilindustrial caracterizado pela forte concorrência e pela acumulação de capital (FRIEDMANN, 2005).

\section{Crise alimentar e humanitária na Europa na Segunda Guerra Mundial}

Embora os números do total de vítimas fatais da Segunda Guerra Mundial sejam controversos - estudos apontam que houve entre 35 e 70 milhões de mortes ligadas às causas do conflito na Europa entre 1939 e 1945 (JUDT, 2005; BEEVOR, 2012) -, é certo que na história da humanidade nenhum outro conflito destruiu tantas vidas humanas, em sua maioria de civis, em um período tão curto de tempo (JUDT, 2005), acarretando em consequências sociais, econômicas, políticas e psicológicas que perduraram por décadas. A "guerra total", de extensão global, mas concentrada na Europa, fez mais vítimas do que qualquer outra em razão da eficiência das armas e do número de países envolvidos. No continente europeu, ela provocou uma devastação física e social sem precedentes (ROSS, 2003). Estima-se que pelo menos 20 milhões do total de mortos tiveram as suas razões ligadas à fome e às doenças relativas à carência de alimentos no continente europeu (COLLINGHAM, 2011). Neste arcabouço, a privação alimentar foi amplamente usada como "arma" de guerra pelas potências envolvidas no conflito. Sem dúvida, essa foi uma das mais cruéis formas de extermínio em massa em função da sua capacidade de levar a fenecimentos lentos e dolorosos.

Diversos países europeus, dominados pelas forças militares nazistas, sob o comando de Adolf Hitler (1889-1945), sofreram com a cruel exploração de suas terras e mão de obra e a insuficiente alocação de bens agroalimentares pelas forças militares da Alemanha entre 1933 e 1945. Com base na justificativa da necessidade de marcar a superioridade da raça germânica, em 1940 o Partido Nacional Socialista elaborou um "Plano de Fome", cuja meta era eliminar entre 20 e 30 milhões de pessoas em território soviético, a maioria poloneses, bielorrussos e ucranianos (LOWE, 2012). Os alimentos produzidos ali deveriam ser redirecionados para abastecer civis da Alemanha, a fim de evitar que seu povo passasse necessidade, ou ainda para alimentar o corpo de homens que serviam nas unidades militares alemãs operando em missões em diversos territórios. De acordo com a estratégia de Hitler, a União Soviética, uma vez conquistada, tornar-se-ia um celeiro agrícola nazista. Essas ações provocaram fome em massa a partir da crise de oferta: desde a invasão alemã às terras soviéticas, que durou de 1941 a 1944, estima-se que 4,2 milhões de cidadãos tenham morrido de fome (SNYDER, 2010), dentre as 16 milhões mortes estimadas na região (JUDT, 2005).

Outros países da Europa também foram obrigados a fornecer recursos para o Wehrmacht ${ }^{95}$ de modo a fazer da Alemanha uma nação moderna, segundo o plano nazista, a partir de altos investimentos em ciência e tecnologia de alimentos. Nos campos de concentração, que iam da França à Ucrânia e da Noruega à Grécia, o valor calórico alimentar fornecido aos prisioneiros no início dos anos 1940 ficou abaixo das 1.200 calorias em média por dia. Em diversas cidades polonesas, a média de ingestão calórica diária após a invasão alemã, que destruiu grande parte da produção de alimentos e privou a população do acesso a eles, manteve-se entre 840 e 900 calorias (COLLINGHAM, 2011; KESTERNICH et al., 2014). Nos guetos de Varsóvia, por exemplo, a dieta alimentar média alcançou a marca de apenas 184 calorias por dia (GUTMAN, 2012), sacrificando a vida de mais de 100 mil judeus no âmbito do plano nazista de "limpeza étnica", ao passo que o regime alimentar alemão à época era de 2.300 calorias diárias em média (COLLINGHAM, 2011). A política anti-semitista nazista incluiu ainda expulsões de judeus, inclusive da Alemanha, os quais foram para guetos e campos de concentração em outros países, e em massacres generalizados (BROWNING; MÄTTHAUS, 2009). Os "bocas inúteis", como os judeus eram chamados pelos nazistas (ZWEINIGER-BARGIELOWSKA, 2011), foram

\footnotetext{
${ }^{95}$ Refere-se às Forças Armadas alemãs durante o Terceiro Reich (1935-1939).
} 
enquadrados nas quotas impostas pelo Terceiro Reich para a eliminação das "raças inferiores" (SNYDER, 2010).

Centenas de milhares de outros "indesejáveis", segundo a ótica nazista, como deficientes mentais e físicos, homossexuais, ciganos e representantes de outras etnias e religiões também foram perseguidos e assassinados (GILBERT, 2009; JUDT, 2005). A sua política de genocídio resultou no holocausto de 6 milhões de judeus (JUDT, 2005; GILBERT, 2009) e outros quase 11 milhões foram prisioneiros de guerra e subjugados a trabalhos forçados em diversos países da Europa e nas áreas sob domínio soviético (BEEVOR, 2012). Com efeito, a luta de Hitler pela supremacia do poder e da raça ariana na Europa foi definida por ele próprio como uma guerra por alimentos, por insumos básicos à vida e por matérias primas (COLLINGHAM, 2011).

A situação mais extrema no que se refere à míngua de alimentos aconteceu no cerco a Leningrado durante novecentos dias por alemães e finlandeses entre os anos de $1941 \mathrm{e}$ 1944. O bloqueio à distribuição de alimentos resultou em uma drástica queda de sua oferta depois que o provimento externo se tornou praticamente impossível. Sitiados, os civis de Leningrado foram colocados no limite da resistência humana, provocando milhares de casos de demência, alucinações e psicoses. Estatísticas oficiais apontam 632 mil mortos, embora outras investigações estimem que esse número tenha alcançado 1 milhão de cidadãos, somente naquela cidade, todas vítimas fatais da fome como política deliberada de extermínio (COLLINGHAM, 2011; ZWEINIGER-BARGIELOWSKA, 2011).

Em contrapartida, os Aliados impuseram condições extraordinariamente adversas aos alemães durante a vigência de sua ocupação no período de 1945 a 1949. Nas zonas de ocupação norte-americana e britânica na Alemanha Ocidental, após a rendição do país, em 1945, a média diária alimentar da população era de 1.200 calorias (JUDT, 2012); em algumas regiões, chegou a 700 (KESTERNICH et al., 2014), sendo que entre 1940-1941, a média havia sido de 2.445 e, em 1943, de 2.078 calorias (JUDT, 2005). Mais de 7 milhões de alemães se tornaram refugiados após serem expulsos de seu país (LOWE, 2012). Estima-se que outros 600 mil foram massacrados pelo exército soviético (SNYDER, 2010).

A escassez de mão de obra após o retorno dos trabalhadores prisioneiros de guerra aos seus países de origem após o cessar-fogo contribuiu para deixar a situação ainda mais precária. A produção de alimentos foi prejudicada com a destruição das propriedades rurais, dos rebanhos e das máquinas. Os Aliados ${ }^{96}$, ao serem confrontados com a necessidade de fornecer grandes quantidades de alimentos para os milhares de alemães prisioneiros de guerra, decidiram cortar o fornecimento a muitos deles, intensificando a crise de fome na Alemanha Ocidental entre 1945 e 1947 (KESTERNICH, et al., 2014, p. 109), a fim de exterminá-los. Isso aconteceu porque, em 1944, os planos delineados no mais alto nível da administração política norte-americana e britânica expressavam sua determinação de destruir de uma vez por todas as aspirações alemãs de se tornar potência mundial, reduzindo-a a uma economia rural, mesmo que isso significasse a fome de milhões de civis (BACQUE, 1995). Por esse motivo, o racionamento de alimentos, o qual alcançou níveis próximos à ingestão calórica média de 2.000 calorias por pessoa em 1943, caiu para 860 em 1945 (JUDT, 2005).

A Alemanha também sofreu com o revés do Exército Vermelho, uma vez que os russos "justificaram" a sua atitude de dificultar o acesso alemão aos alimentos básicos em razão do que haviam sofrido nas mãos daquele país (COLLINGHAM, 2011). Cerca de 8 milhões de vidas foram banidas da Alemanha como resultado da submissão do país à fome deliberada, às doenças, às prisões de guerra e à política de expulsão dos territórios ocupados depois de finalizado o período de hostilidades (BACQUE, 1997).

As consequências da fome como arma de guerra foram cruéis e devastadoras. Além do continente europeu e da zona soviética, houve milhões de vítimas fatais da carência alimentar em outras localidades do mundo, como Japão, China, Etiópia, Índia, Indonésia,

\footnotetext{
96 União Soviética, Estados Unidos, Reino Unido e França foram as potências do bloco dos Aliados, que confrontaram as potências do Eixo (Alemanha, Itália e Japão) na Segunda Guerra Mundial.
} 
Vietnã, Filipinas etc. (WEIBERG, 2010). Soluções para o quadro dramático delineado no imediato pós-conflito demandavam ações urgentes.

\section{As primeiras reações dos governos europeus à crise}

O desfecho da Segunda Guerra não pôs fim à violência, ao desespero e à miséria na Europa. Depois que o conflito cessou, revelaram-se as suas consequências para além das mortes: miséria, migrações em massa, subnutrição, alastramento de doenças, crianças órfãs e traumatizadas, queda do número de homens em proporção ao de mulheres e da força de trabalho em termos absolutos, além do alto índice de suicídio. Esses fatos deixaram marcas traumáticas, tanto físicas quanto psicológicas, difíceis de serem superadas, tanto nas sociedades da Europa como da União Soviética (KESTERNICH et al., 2014).

De modo geral, o valor nutricional da dieta alimentar era insuficiente para garantir saúde e uma vida longa à população europeia, principalmente após um extenso período de privações. Em muitos países, calculava-se que naquele período um cidadão jovem precisava ingerir entre 2.800 e 3.000 calorias diárias, sendo que em condições de treino militar e nos campos de batalha a baixas temperaturas, esses valores deveriam ser superiores, em torno de 4.000 (COLLINGHAM, 2011). A escassez de alimentos, somada ao desemprego e à falta de atendimento médico, gerou greves e insatisfação da população, implicando em um ambiente social que se manteve ainda mais instável. Para agravar a situação, aqueles agricultores que ainda conseguiam cultivar alimentos mostraram-se relutantes em fornecê-los às cidades. Além disso, a maioria das moedas europeias havia perdido valor e, mesmo quando os cidadãos tinham meios para comprar bens, a oferta disponível era insuficiente (JUDT, 2005).

O estado precário das economias das nações europeias após o conflito exigia a intervenção imediata dos governos para organizar programas de recuperação e superar a destruição física e a pífia e insuficiente produção agrícola e de bens básicos. Neste fluxo, a resposta das autoridades à crise alimentar foi determinar critérios de priorização para o fornecimento de alimentos, a fim de atender às necessidades das forças armadas, em primeiro lugar. Em seguida, o sistema de regulação do consumo foi estendido à população nas cidades e no campo (JOSLING et al., 2009). Seu objetivo era evitar maior precariedade, o que poderia provocar no limite outro conflito geopolítico de grandes proporções.

Ao submeter os gêneros alimentícios de primeira necessidade ao regime de racionamento, as autoridades públicas nacionais passaram a tomar para si a responsabilidade da reorganização da produção e da partilha de alimentos para a população, interferindo nas condições nacionais de oferta e demanda (THEIEN, 2009). Esse sistema foi claramente projetado para atender às necessidades dos diferentes segmentos sociais, a partir do reconhecimento dos segmentos sociais prioritários por parte dos governos. Para os consumidores, os quais consideravam desiguais os sacrifícios impostos à distribuição, o desenvolvimento do mercado paralelo de alimentos, constituiu uma solução para transgredir os critérios públicos e o aumento de preços que potencializavam o enriquecimento de traficantes (ZWEINIGER-BARGIELOWSKA, 2011). Segundo eles, o regime de racionamento favorecia os mais ricos e prejudicava os mais pobres. Como consequência disso, multiplicavam-se os desequilíbrios entre aqueles que queriam produzir e vender por altos níveis de preços e os consumidores que precisavam comprar bens por preços considerados "aceitáveis". Longe de desaparecer, as injustiças aumentavam nos países europeus e a penúria persistia nos anos seguintes ao fim das hostilidades.

Em função da guerra, a renda dos produtores e trabalhadores rurais declinou drasticamente e famílias inteiras caíram abaixo da linha de pobreza, abrindo espaço para o êxodo rural, além dos milhões de refugiados vítimas da guerra. Também houve dificuldades no fornecimento de insumos para a geração de energia, particularmente por conta do confisco de matérias primas essenciais para a sua produção (KLEMANN; KUDRUASHOV, 2013). Os rigorosos invernos que atingiram a Europa no imediato pós-Segunda Guerra agravaram as condições de penúria em que se encontrava a população europeia 
(ZWEINIGER-BARGIELOWSKA, 2011). Nesse contexto, os países da Europa Ocidental, os quais haviam sido, em geral, industrializados e urbanizados, após o fim do conflito se encontravam duramente penalizados e fortemente dependentes da importação de bens de consumo básicos, sobretudo norte-americanos. Depois do fim dos confrontos, essa dependência foi vista pelos líderes como uma questão de fragilidade política e estratégica do seu país (ZOBBE, 2001).

Nesse contexto, muitas nações aliadas dos Estados Unidos receberam ajuda daquele país com o fim conter a expansão comunista na Europa na esteira da Guerra Fria. O mais importante deles foi o Plano de Recuperação Econômica Europeia, conhecido como Plano Marshall (1948-1951), cujo propósito era compensar o massivo déficit de dólares das economias europeias, ávidas para comprar insumos energéticos, matérias primas e diversos tipos de bens de consumo, além dos itens considerados essenciais para a sua reconstrução. Essa foi a principal fonte que sustentou as demandas dos países da Europa Ocidental por bens agroalimentares provenientes do mercado norte-americano, introduzindo mecanismos de ajuda externa (FRIEDMANN, 1995). Do total recebido até 1951 pelos países europeus, próximo a $60 \%$ dos recursos do Plano Marshall foram gastos com produtos primários e intermediários, como alimentos, rações, fertilizantes, e o restante com bens industrializados e semiacabados. Um sexto do valor foi destinado a gastos com combustíveis e outro sexto com máquinas, veículos e outros bens (LONG; EICHENGREEN, 1991). A agricultura foi considerada pelos representantes políticos europeus um setor fundamental para garantir a estabilidade no longo prazo ao eliminar a fome e a miséria do continente (LASCHI, 2011).

Diante desse cenário, governos tiveram de buscar soluções públicas, tendo em vista que garantir a segurança alimentar ${ }^{97}$ se tornou a preocupação mais urgente de todos os países europeus recém-saídos do conflito e temerosos por novas hostilidades (COLLINGHAM, 2011). A segurança se relacionava aos altos preços, que corroíam o poder de compra dos trabalhadores, inclusive do campo, porque estavam mais pobres ou sem renda suficiente para comprar alimentos; e à escassez, que suscitava perturbação social (KOESTER e EL-AGRAA, 2003, p 360). Some-se a isso o fenômeno da volatilidade de preços dos produtos agroalimentares, derivado das incertezas relacionadas às condições climáticas, à qualidade do solo e às doenças, que incidiam sobre as culturas agrícolas.

Assim, a partir da percepção da necessidade de alcançar autossuficiência ${ }^{98}$ e a soberania alimentar como uma condição para garantir a segurança e promover a paz, as lideranças políticas europeias se concentraram em incentivar e a proteger seus mercados agrícolas domésticos a partir dos anos 1950. Por isso, esses governos intervieram no setor, na maioria dos casos, utilizando-se de vários tipos de instrumentos públicos (APARICIO; PINILLA; SERRANO, 2006).

\section{O estado de bem-estar social e uma proposta de coordenação internacional da oferta de alimentos}

Ansiosas por evitarem quedas futuras no desempenho econômico, enfrentar o desemprego em massa e dirimir qualquer risco de instauração de regimes políticos não democráticos após o fim da Segunda Grande Guerra, os líderes admitiram que o Estado deveria se envolver ativamente na reorganização, na direção e na regulação da economia, fornecendo as condições necessárias para sua recuperação e ampliação da demanda efetiva. Por conseguinte, as diretrizes econômicas adotadas pelos governos da Europa Ocidental se alinharam às regras e às instituições multilaterais estabelecidas na Conferência

\footnotetext{
97 O termo "segurança alimentar", como tal, não foi articulado até 1974. Somente em meados dos anos 1980 passou a fazer parte do discurso oficial das organizações (OTERO, PECHLANER; GÜRCAN, 2013, p. 267). Segundo a FAO (2008): "Há segurança alimentar quando todas as pessoas, a todo o momento, têm acesso a alimentos suficientes de forma segura, de modo que as suas necessidades físicas, sociais e econômicas sejam satisfeitas contribuindo para uma vida ativa e saudável" (FAO, 2008).

98 Autossuficiência alimentar é definida por Otero, Pechlaner e Gürcan (2013) como a capacidade de um país de fornecer alimentos básicos para o seu povo. Sua dependência de importações não deveria exceder $20 \%$ da oferta interna de uma determinada cultura agrícola.
} 
de Bretton Woods, de 1944, as quais foram instauradas para promover a retomada do crescimento e o gerenciamento da economia capitalista internacional, de acordo com os interesses e os parâmetros dos Estados Unidos. A partir do consenso político sobre a nova ordem econômica liberal, as potências aliadas capitalistas se comprometeram a promover políticas de pleno emprego e garantir o bem-estar social, elementos os quais, no seu entendimento, não seriam alcançados simplesmente com a liberdade das forças de mercado.

Assim, os governos mostravam estar convencidos de que a abertura das economias através do comércio livre, com "direito" ao uso do controle dos fluxos de capitais, era o melhor caminho a ser seguido a fim de melhorar a sua distribuição de renda (HELLEINER, 1995). Os entraves ao comércio internacional seriam removidos promovendo incentivos para a sua liberalização e especialização produtiva. Neste sentido, diversos países da Europa Ocidental assinaram o Acordo Geral de Tarifas e Comércio em 1947. As regras do Sistema Monetário Internacional deveriam garantir a confiança na moeda de referência, o dólar, o ajustamento não inflacionário do balanço de pagamentos das economias e a liquidez requerida pelas transações em fase de expansão. As taxas de câmbio foram fixas ou vinculadas à moeda norte-americana; caso um país precisasse alterar a sua taxa de câmbio, deveria consultar e ter o consentimento do Fundo Monetário Internacional (FMI). Ao Banco Internacional para a Reconstrução e o Desenvolvimento (BIRD) coube fomentar a reconstrução e o desenvolvimento econômico dos Estados pós-Guerra.

Para além dos ajustes macroeconômicos, crescia nos países da Europa Ocidental pressão social para que fossem realizadas ações políticas voltadas para a construção de uma sociedade mais humana e preparada para enfrentar adversidades, cuja intenção, além de superar os eventos passados, era evitar desastres futuros (MILWARD, 1980). Por essa razão, e dadas as condições de penúria em que se encontrava a população de muitos países, difundia-se nos círculos sociais a concepção de que o Estado teria de ser o provedor das necessidades domésticas básicas dos cidadãos. Neste sentido, a classe trabalhadora e as coalizões políticas europeias tiveram papel importante na condução das mobilizações coletivas na busca por direitos sociais (ESPING-ANDERSEN, 1999), pois, em vários aspectos, as conquistas na área do bem-estar refletiram sua luta e seu compromisso com a causa. Por um lado, partidos políticos bem organizados, que representavam os trabalhadores, aceitaram a retomada das atividades capitalistas gerenciadas pela imposição de regulações em troca de amplos programas sociais bancados pelo governo. Por outro, aqueles partidos, os quais falavam em nome dos empresários, concordaram em apoiar uma rede de seguridade social com o pagamento de contribuições mediante a contrapartida da adoção de planos de recuperação da produção industrial por parte do Estado (CHALISZ e DIMOND, 2015).

A despeito da variedade de formas por meio das quais as políticas de bem-estar social se manifestaram na Europa, a erradicação da pobreza, a diminuição da desigualdade social e a distribuição da renda constituíram seu foco durante as três décadas seguintes ao final da Segunda Guerra Mundial. Logo, além de ser eixo base para a formulação das políticas macroeconômicas direcionadas à recuperação e à estabilidade das economias, a política de emprego e de salários foi reconhecida como um direito dos trabalhadores, assim como o acesso aos serviços públicos (ESPING-ANDERSEN, 1999).

Em síntese, a construção da ordem econômica liberal no pós-Segunda Guerra implicou em uma dupla tarefa para os governos europeus: restabelecer medidas justas de liberalização do comércio internacional e estabilidade cambial e monetária e, ao mesmo tempo, permitir que as políticas domésticas pudessem garantir o bem-estar da população. Simultaneamente, o "compromisso com o liberalismo dirigido" (RUGGIE, 1982) 99 consubstanciava-se na adoção de políticas keynesianas (LONG; EICHENGREEN, 1991). Essas ações foram decisivas para a retomada dos níveis de produção, crescimento

\footnotetext{
99 O termo "liberalismo dirigido" está relacionado ao "embedded liberalism", utilizado por John Ruggie (1982), cujo trabalho tem como objetivo discutir como a moeda e o comércio gerenciados pelo Estado afetaram a evolução da economia internacional no pós-Segunda Guerra Mundial.
} 
econômico e prestação de serviços públicos aos cidadãos europeus nas décadas seguintes. De modo geral, as economias da Europa Ocidental cresceram a altas taxas na "era de ouro do capitalismo" até os anos 1970 e conseguiram reduzir significativamente seus níveis de insegurança social. Muitos governos realizaram políticas sociais abrangentes e de longo prazo, além de grande volume de gastos públicos em infraestrutura e investimentos em diversas áreas. Os sistemas públicos substituíram ou deslocaram cooperativas e empresas na provisão de serviços, ampliando sua cobertura socioeconômica e territorial (GOUGH, 2008). Essas regulações governamentais modificavam o comportamento dos agentes privados à medida que o Estado os taxava ou subsidiava ou ainda impunha a cobrança de impostos progressivos sobre a renda das famílias.

Dadas as marcas e traumas deixados pela história, a fome foi entendida como uma violação a um direito humano básico, o da alimentação. À época, organizações intergovernamentais e acadêmicas propagavam a importância de se fazer esse reconhecimento. Dois dos mais importantes códigos de direitos humanos internacionais firmados - a Declaração Universal dos Direitos Humanos ${ }^{100}$, aprovada pela Assembleia Geral das Nações Unidas (ONU), em 1948, e o seu descendente, o Pacto Internacional sobre os Direitos Econômicos, Sociais e Culturais, assinado em 1966 pelos membros da mesma Assembleia - não deixavam dúvidas da sua recognição acerca da relevância de tornar o acesso à alimentação um direito respeitado em todas as partes do mundo. Enquanto a Declaração tratava a alimentação como um direito social, os EstadosSignatários reconheceram no Pacto o direito fundamental de toda pessoa estar protegida contra a fome. Ele também indicava a adoção, individualmente e/ou através da cooperação internacional, de medidas e projetos concretos para erradicá-la (BULTRINI, 2014). Com efeito, esses foram os primeiros passos dados rumo a uma nova era do Direito Moderno, que passou a instituir jurisprudência sobre crimes praticados contra a humanidade em casos nos quais políticas e ações repercutiam na submissão deliberada da população civil à carência de alimentos ou ao prolongamento dessa condição (MARCUS, 2003).

Neste quadro, a segurança alimentar também foi pensada no amplo debate das teorias do desenvolvimento econômico e das mudanças necessárias para a instituição de um regime internacional de alimentos (SHAW, 2007). A preocupação com a garantia da produção e da distribuição de alimentos no mercado internacional estimulou políticos e gestores públicos dos países aliados a considerarem a imprescindibilidade da coordenação permanente entre as políticas agrícolas nacionais, que fosse capaz de criar equilíbrio de longo prazo entre a oferta e a demanda mundial por alimentos, logo após o fim da Segunda Guerra. Em outubro de 1946, John Boyrd Orr, secretário-geral de origem britânica da Food and Agriculture Organization (FAO), agência da ONU, oficialmente fundada em 1945, em Québec, com intenção de agregar os debates de temas como nutrição, saúde, agricultura, comércio e indústria de alimentos, propôs a criação de um comitê supranacional para garantir a oferta mundial de alimentos e eliminar as flutuações de preços dos bens alimentares no curto prazo e desequilíbrios de oferta no longo prazo, por meio da cooperação das potências do setor (SHAW, 2007). O World Food Board (WFB), como foi chamado, ficaria responsável por essas funções de modo permanente a partir da provisão de um fundo destinado a este fim, além de gerir reservas para qualquer emergência.

Entretanto, o medo da introdução de controles da produção, caso o WFB fosse criado como uma instituição autônoma, implicou que, em 1947, em Washington, Estados Unidos, Canadá e Reino Unido rejeitassem a proposta nos moldes apresentados. Com isso, o plano de fundação do WFB foi arquivado e a FAO se tornou somente uma agência de estudos e consultoria do Sistema ONU (SORESENSEN, 2008). A não aprovação do WFB pelos Estados Unidos e pelo Canadá se explicava pelo potencial do seu mercado de aumentar a oferta doméstica de alimentos no pós-1945, enquanto as sociedades europeias arruinadas lutavam para combater a fome por meio da articulação e aplicação de planos absolutamente dependentes do apoio dos seus governos. Ainda assim, o projeto de

\footnotetext{
100 O artigo 25, parágrafo 1, da Declaração Universal dos Direitos Humanos afirma: "Todos têm direito a um
} padrão de vida adequado em relação à saúde e ao seu bem-estar e de sua família...". 
constituição do WFB serviu de inspiração para outros apresentados mais adiante. Depois de 1945 , as economias desenvolvidas se concentraram em fomentar programas nacionais fortemente protecionistas e subsidiados pelos governos no setor agrícola face falta de uma instituição efetiva de coordenação internacional da produção, oferta e comércio de bens agrícolas (NÖEL, 1988).

\section{Modernização, proteção e abundância agrícola na Europa}

Pelos motivos mencionados, a agricultura, que tradicionalmente teve um papel central no desenvolvimento das economias industrializadas da Europa, foi vista pelos seus governos como um setor ainda mais excepcional no pós-Segunda Guerra (FRIEDMANN, 1995). Além dos motivos discutidos, o discurso com base na herança histórica do campo e a necessidade de manutenção das propriedades rurais familiares, as quais eram percebidas pela população como parte do seu patrimônio, foi um argumento muito repetido em diversos países europeus, tanto pela elite política quanto pelos grupos de interesses organizados do setor, os quais pressionaram seus representantes para tomar ações as quais Ihes fossem convenientes (KRÖGER, 2009). O esforço de recuperação no pós-Segunda Guerra implicou no aumento dos estímulos à proteção do setor agrícola de maneira significativa, com a adoção de programas conduzidos pelo Estado, cujos fundos se destinavam à realização de mudanças estruturais no campo. Entre o final dos anos 1940 e início dos 1950, os governos europeus incitaram o aumento da produção agrícola através do fomento do progresso tecnológico em um ritmo até então sem precedentes (VEIGA, 1994). Foram concedidos estímulos públicos à produção por meio de subsídios, como financiamento a baixas taxas a partir da criação de instituições de crédito específicas, programas cujos recursos públicos se destinavam às áreas específicas de pesquisa, extensão e melhorias técnicas e à criação de instituições financeiras voltadas a subvencionar exclusivamente empréstimos destinados à atividade agrícola (MUIRHEAD; ALMAS, 2012). Vultosos gastos foram canalizados por órgãos fomentadores estatais com o fim de racionalizar e maximizar a produção agrícola, uma vez que os governos europeus acreditavam que o incremento da produtividade era a melhor maneira de expandir a produção e, consequentemente, aumentar a oferta de alimentos disponível aos consumidores (ALVAREZ-CUADRADO; PINTEA, 2008).

$\mathrm{Na}$ verdade, o crescimento da produtividade do setor agroalimentar se ligava a um fenômeno mais amplo em curso na Europa: a difusão tecnológica graças à revolução agrícola contemporânea (MAZOYER e ROUDART, 2006), processo que acontecia na esteira da evolução do capitalismo industrial. As áreas de transportes, telecomunicações, química, mecânica e genética potencializaram a produção de fertilizantes sintéticos, herbicidas e pesticidas, permitiram a seleção de variedades de espécies de plantas e animais, promoveram a construção de sistemas drenagem, o aperfeiçoamento de técnicas de plantio, além de difundirem a mecanização avançada. A especialização da força de trabalho foi tomada pelos governos como elemento essencial para a recuperação da agricultura a partir da melhoria do ensino técnico, aprimoramento das pesquisas científicas e criação de institutos de investigação (MARTIN; LANGTHALER, 2009).

A "onda" de motomecanização, que havia começado ainda antes da Primeira Guerra Mundial, espalhou-se pela Europa Ocidental entre o fim dos anos 1940 e o início dos anos 1950. O amplo uso de máquinas e tratores possibilitou a extensão da área plantada ao substituir a tração animal pela mecanizada, avultando, assim, a capacidade produtiva média do campo. O número médio de tratores por trabalhador saltou de 0,045 em 1950 para 0,238 em $1962^{101}$ (MARTÍN-RETORTILLO; PINILLA, 2013, p. 30-33), resultante na elevação da taxa média de produtividade do setor. A motorização do transporte rodoviário, marítimo e ferroviário expandiu sua capacidade de carregamento e velocidade e, consequentemente, os custos dos fretes caíram. Numerosas inovações foram adotadas também na pecuária, como a máquina de ordenhar e os tanques refrigerados para armazenagem. Como

101 A média incluiu os dados dos seguintes países: Áustria, Bélgica, Luxemburgo, Dinamarca, França, Irlanda, Países Baixos, Suíça e Reino Unido. 
consequência disso, em muitos mercados europeus, os preços finais dos bens alimentares básicos, particularmente os de grãos, começaram a declinar. Por outro lado, a introdução do novo paradigma tecnológico no campo dos países da Europa Ocidental resultou num acentuado êxodo rural. Cerca de $17 \%$ da população europeia migrou do campo para áreas urbanas entre os anos 1950 e 1970 (ALVAREZ-CUADRADO; PINTEA, 2008). Particularmente em alguns países, como a Itália por exemplo, que tinham grande proporção da população vivendo no campo em relação ao total, o descontrole do êxodo rural era uma questão premente para seus governos. Para efeito de comparação, identifica-se: "A taxa de participação da mão de obra da agricultura no total da população economicamente ativa era de $29 \%$ na França, 25\% na Alemanha Ocidental e 41\% na Itália em 1949. Em 1960, elas alcançaram 22\%, 14\% e 33\%, respectivamente" (SALMON; WOLFESPERGER, 2007, p. 28).

No amplo espectro de proteção do setor rural, foram ainda impostos pelos governos muitos limites ao comércio externo por meio da implementação de quotas de importação e de tarifas (FEDERICO, 2005), além de outros tipos de controles quantitativos e qualitativos considerados necessários para manter o equilíbrio do setor agrícola nos mercados da Europa Ocidental (BROADBERRY, 2006). Alguns introduziram ainda sistemas de estabilização artificial de preços, normalmente pela determinação de altos patamares mínimos garantidos pelo governo (CHANG, 2009). Leis foram aprovadas, criando câmaras de comércio e de armazenamento de cereais, ração, leite e derivados, gordura e carne, entre outros, com o fim de regular o volume de produção comercializado nos mercados domésticos. Consequentemente, "a taxa nominal global de proteção da agricultura na Europa cresceu em torno de dois terços em média entre 1956-57 e 1968-69" (ANDERSON; TYERS, 1992, p. 50). Dessa forma, o gerenciamento rigoroso sobre a oferta do mercado doméstico manteve os preços agrícolas relativamente estáveis, como queriam os produtores, enquanto a produção foi encorajada nas pequenas propriedades, em sua maioria, familiares (COPPOLARO, 2010).

Esse contexto abriu oportunidades para importantes discussões entre médicos, nutricionistas e cientistas sobre o desenvolvimento de estudos acerca do valor nutricional e calórico dos alimentos necessário para o consumo de um ser humano saudável e do papel das várias vitaminas e minerais contidos nos alimentos, que poderiam influenciar o desempenho dos combatentes nos conflitos, considerando-se os hábitos alimentares de cada população (ZWEINIGER-BARGIELOWSKA, 2011). Desenvolveu-se, assim, a ciência da nutrição, com o objetivo de apontar soluções e receitas para crises alimentares e explorar novas fontes nutricionais (THEIEN, 2009), abrindo espaço para que os governos encorajassem os produtores rurais a investirem no plantio de alimentos com taxas nutricionais mais altas.

Dessa forma, a partir dos anos 1950, as economias europeias entraram em uma segunda fase na qual o investimento privado substituiu os gastos públicos como o motor de crescimento. Houve expansão dos investimentos privados em razão da melhoria da infraestrutura, das técnicas, do controle do mercado interno e da sua proteção e das condições dadas aos produtores e trabalhadores rurais (ÁLVAREZ-CUADRADO, 2005). Tais elementos se caracterizaram pelo contínuo crescimento da taxa de inversões paralelamente a de consumo, cujos padrões foram completamente restaurados. A agricultura das nações europeias se encontrava na esteira da transição da produção agrícola internacional de baixa produtividade para um sistema agrícola caracterizado pelo aumento do emprego do fator de produção capital vis-à-vis o trabalho, resultando em um sistema cada vez mais produtivo e consequentemente competitivo e internacionalizado (FEDERICO, 2005). As variações da produção agrícola bruta per capita (crescimento percentual médio anual por país entre 1952-1959) foram de 8,5\% na Alemanha Ocidental, 4,3\% na França, 4,8\% na Itália, $6,1 \%$ nos Países Baixos, 5,4\% no Reino Unido (FAO, 1963). Em vista disso, em pouco tempo, as propriedades, que se tornavam cada vez mais eficientes, deixaram de se voltar essencialmente à produção para garantir o suprimento alimentar básico do seu mercado doméstico e visaram apoiar à acumulação de capital dos 
grandes produtores rurais, os quais formavam segmentos sociais bem organizados em termos de poder político.

Como consequência desse processo, o nível dos salários médios no campo cresceu, apresentando tendência de aumento real, em média de 12\% no período 1951-1970, e as pessoas passaram a poder comprar bens de maior valor agregado (ALVAREZCUADRADRO, 2005, p. 4). As taxas médias de crescimento percentuais anuais da renda per capita entre 1952-1954 a 1958-1959 (a preços constantes) foram, respectivamente: 7,4 na Alemanha Ocidental, 3,7 na França, 6,3 na Itália, 4,0 nos Países Baixos, 2,2 na Bélgica, 2,3 no Reino Unido, 6,8 na Áustria, 2 na Noruega, 2,9 na Dinamarca e 3,1 na Suécia (FAO, 1963). O valor calórico médio das dietas alimentares também foi completamente recuperado: entre 1948-1950 na Alemanha Ocidental era de 2730 e alcançou 2990 entre 1958-1959. Os valores para os mesmos períodos da França foram de 2800 e 2950; Países Baixos, 2830 e 2940; Itália, 2350 e 2650 e Bélgica, 2670 e 3050 calorias, respectivamente (FAO, 1960).

Portanto, a reconstrução pós-Segunda Guerra Mundial fez mais do que somente recolocar as economias europeias na trajetória do crescimento econômico e garantir a proteção social, pois proporcionou aumento da produção e da produtividade agrícola, da renda rural e do consumo desses bens, realocando ainda a mão de obra do campo para a cidade.

\section{Conclusão}

Este artigo discutiu como as consequências da crise humanitária e alimentar vivenciadas pela Europa do período de guerras foram determinantes para os planos dos Estados europeus de recuperarem seu setor agrícola. Tendo em vista o êxito das políticas públicas na maioria deles, em um curto espaço de tempo, os bons resultados lhes permitiram superar a carência e chegar à abundância no mercado de alimentos. As inovações técnicas e institucionais de pesquisa agrícola, a mecanização do campo e a produção de fertilizantes artificiais se espalharam pela Europa Ocidental (ANDERSON, 2009). A agricultura se tornou uma significativa máquina de produção, sobretudo face ao acréscimo do uso do fator capital em detrimento do fator trabalho (FEDERICO, 2005). O rápido crescimento da produtividade agrícola teve como consequência a realocação maciça de mão de obra do campo em atividades urbanas e o aumento sensível da renda dos produtores e trabalhadores rurais, da demanda agregada e das economias de escala. As propriedades rurais essencialmente familiares foram se tornando verdadeiras "empresas agrícolas", tanto em termos de intensidade de capital empregado quanto do alto grau de especialização, da crescente acumulação de capital e diferenciação dos padrões produtivos, os quais marcaram as transformações estruturais na esteira do processo de modernização.

O que ocorreu nos mercados agrícolas da Europa Ocidental, a partir da metade do século XX, foi o contínuo apoio estatal à agricultura não mais de propósitos assistencialistas, como no imediato fim da Segunda Guerra, mas voltado à otimização organizacional da agricultura de acordo com os objetivos de aumento da especialização, da eficiência e da competição pela liderança de mercado. O Estado foi a instituição que esteve no início desse processo, mas sua intenção, depois de certo tempo, foi estimular o retorno dos investimentos privados. Sua proteção e apoio ao sistema agrícola direcionaram, canalizaram e encorajaram o desenvolvimento de um "regime intensivo de alimentos", ou seja, seu papel foi determinante entre o final dos anos 1940 e início dos anos 1970 para promover mudanças estruturais nos mercados agrícolas europeus (MUIRHEAD; ALMAS, 2012), que a partir da superação da escassez funcionaram não mais segundo a lógica assistencialista, mas de acordo com a racionalidade da produção máxima e eficiente da agricultura, perseguindo objetivos de aumento da especialização e da produtividade.

Em decorrência disso, a dependência dos países europeus das importações agrícolas do mercado internacional caiu, os preços da maioria dos bens se estabilizaram ou até mesmo descenderam e houve menor agitação social no período se comparado ao 
imediato pós-Guerra, a despeito das incertezas da Guerra Fria. Embora o cenário fosse de recuperação e abundância no campo, grande parte da população continuou apoiando as ações públicas de proteção e estímulo à agricultura nas três décadas seguintes, porque viam o ambiente rural como um símbolo histórico da sociedade e responsável pela produção de bens garantidores da vida após terem experimentado as implicações terríveis da fome como arma de guerra. Foram esses aspectos, qualitativos e quantitativos, decorrentes da modernização agrícola, os quais marcaram as mudanças na agricultura da Europa Ocidental no pós-Segunda Guerra.

\section{Referências bibliográficas}

ALVAREZ-CUADRADO, Francisco; PINTEA, Michaela. A quantitative exploration of the golden age of european growth: structural change, public investment, the Marshall Plan and intra-European trade.

Economics Research Working Paper Series, n. 43, p. 1-34, 2008.

ANDERSON, Kim. Five Decades of agricultural distortions. In: ANDERSON, Kym. (Orgs.).

Distortions to agricultural incentives: a global perspective, 1955-2007. Washington, D.C.: World Bank and Palgrave Macmillan, 2009, p. 3-64.

ANDERSON, Kim; TYERS, Rod. Japanese rice policy in the interwar period: some consequences of imperial self-sufficiency. Japan and the World Economy, v. 4, n. 2, p. 103-127, 1992.

APARICIO, Gema; PINILLA, Vicente; SERRANO, Raúl. Europe and the International Agriculture and Food Trade, 1870-2000. In: INTERNATIONAL ECONOMIC HISTORY CONGRESS, Helsinki.

Papers... Helsinki: University of Helsinki. 2006.

BACQUE, James. Crimes and mercies. London: Little, Brown \& Co, 1997.

BACQUE, James. Outras perdas. São Paulo: Edições ASA, 1995.

BEEVOR, Antony. The Second World War. Little Brown and Company, 2012.

BROWNING, Cristopher; MÄTTHEUS, Jürgen. The origins of the final solution: the evolution of nazi jewish policy September 1939-March 1942. Lincoln: University of Nebraska Press. Jerusalem: Yad Vashem, 2004.

BULTRINI, Dubravka Bojic. O direito à alimentação no quadro internacional dos direitos humanos e nas Constituições. Cadernos de Trabalho sobre Direito à Alimentação. Organização das Nações Unidas para a Alimentação e a Agricultura, Roma, 2014.

COLLINGHAM, Leslie. The taste of war: World War Two and the battle for food. London: Allen Lane, 2011.

COPPOLARO, Lucia. The political economy of reduction in Western Europe (1947-1967): between multilateralism and regionalism. Conference..., Instituto Figuerola, Madrid: Universidad Carlos de Madri, 2010.

CHANG. Ha-Joon. Rethinking public policy in agriculture: lessons from distant and recent. Rome: FAO, 2009.

ESPING-ANDERSEN, Gosta. Social foundations of postindustrial economies. Oxford, U.K.: Oxford University Press, 1999.

FOOD AND AGRICULTURE ORGANIZATION (FAO). An introduction to the basic concepts of food security. Rome, 2008.

FOOD AND AGRICULTURE ORGANIZATION (FAO). The state of food in agriculture. Rome, 1960; 1963.

FEDERICO, Giovanni. Feeding the world, 1800-2000. Princenton: Princenton University Press, 2005.

FRIEDMANN, Harriet. From colonialism to green capitalism: social movements and the emergence of food regimes. In: BUTTEL, Fredrick.; McMICHAEL, Philip. (Orgs.). New directions in the sociology of international development. Amsterdam: Elsevier, 2005. p. 227-267. 
FRIEDMANN, Harriet. Food politics: new dangers, new possibilities. In: McMICHAEL, Phillip. (Org.). Food and agrarian orders in the world economy. Westport: Praeger, 1995. p. 15-33.

FRIEDMANN, Harriet; McMICHAEL, Philip. Agriculture and the state system: the rise and decline of national agricultures, 1870 to the present. Sociologia Ruralis, v. XXIX, n. 2, p. 93$117,1989$.

GILBERT, Mark. From war to Cold War. In: LARRES, Klaus (Org.). Companion to Europe since 1945. Oxford: Wiley-Blackwell, 2009. p. 1-24.

GOUGH, lan. European welfare states: explanations and lessons for developing countries. ANIS AHMAD, Dani; HARJAN, Haan (Orgs.) Inclusive states: social policy and structural inequalities. Washington, World Bank Publications, 2008. p. 3-38.

GUTMAN, Roy. Resistance: the Warsaw Ghetto uprising. Boston: Houghton Mifflin Harcourt, 2012.

CHALISZ, Claudia; DIAMOND, Patrick. Predistribution: A new governing prospectus for the centre-left. In: CHALISZ, Claudia; DIAMOND, Patrick (Orgs.). The predistribution agenda. Policy Network, 2015. p. 1-21.

HELLEINER, Eric. Explaining the globalization of financial markets: bringing states back in. Review of International Political Economy, v. 2, n. 2, p. 315-41, 1995.

JOSLING, Tim et al.. Understanding International Trade in agricultural products: one hundred years of contributions by agricultural economists. American Journal of Agricultural Economics, v. 92, n. 2, p. 424-446, 2009.

JUDT, Tony. A history of Europe since 1945. New York: The Penguin Press, 2005.

KESTERNICH, Iris et al.. The effects of World War II on economic and health outcomes across Europe. Review of Economics and Statistics, v. 96, p. 1, p. 103-118, 2014.

KLEMANN, Hein; KUDRYASHOV, Sergei. Occupied economies. An economic history of nazioccupied Europe, 1939-1945. London: Berg, 2013.

KOESTER, U.; EL-AGRAA, A. The common agriculture policy. In: EL-AGRAA, A. (Org.). The EU economics and policies. Essex: Pearson, 2003. p. 354-390.

KRÖGER, Sandra. Ideas, interests or institutions? The drivers of recent reform of the Common Agricultural Policy. EIF Working Paper, n. 2, p. 1-35, 2009.

LASCHI, Giuliana. Agricultores y sus intereses en el processo de integración: ¿Qué política par qué tipo de agricultura? Puente@Europa, v. IX, n. 1, Jun 2011, p. 34-41.

LOWE, Keith. Savage continent: Europe in the aftermath of World War II. London: Penguin Books, 2012.

LONG, Bradford; EICHENGREEN, Barry. The Marshall Plan: history's most successful structural adjustment program. CONFERENCE ON POST-WORLD WAR II EUROPEAN RECONSTRUCTION, Papers... Hamburg, 1991.

MARCUS, David. Famine crimes in international law. The American Journal of International Law, v. 97, n. 2, p. 245-281, 2003.

MARTÍN-RETORTILLO, Miguel; PINILLA, Vicente. Patterns and causes of growth of european agricultural production, 1950-2005. Documentos de Trabajo, n. 1302, p. 1-36, 2013.

MARTIN, John; LANGTHALER, E. Paths to productivism: agricultural regulation in the Second World War and its post-war legacy in Great Britain and German-Annexed Austria. In: BRESSLEY, Paul; SEGERS, Yves; VAN MOLLE, Leen. (Orgs.). War, agriculture and food: rural Europe from the 1930s to the 1950s. New York: Routledge, 2012. p. 55-74.

MAZOYER, M.; ROUDART, L. A history of world trade agriculture: from the neolithic age to the current crisis. London: Earthscan, 2006.

MILWARD, Alan. The reconstruction of Western Europe, 1945-1951. London: Methuen \& Co, 1984. 
MUIRHEAD, Bruce; ALMAS, Reidar. The evolution of Western agricultural policy since 1945. In: ALMAS, Reidar; CAMPBELL, H. (Orgs.). Rethinking agricultural policy regimes: food security, climate change and the future resilience of global agriculture. Bingley: Emerald, 2012. p. 23-49.

OTERO, Gerardo; PECHLANER, Gabriela; GÜRCAN, Efe. The Political Economy of "Food Security" and Trade: Uneven and Combined Dependency. Rural Sociology, v. 78, n. 3, p. 263-289, 2013. ROSS, Stewart. Cause and consequences of the Second World War. London: Evans Brothers, 2003.

RUGGIE, John. International Regimes, transactions, and change: embedded liberalism in the postwar economic order. International Organization, v. 36, n. 2, p. 379-415, 1982.

SALMON, Pierre; WOLFELSPERGER, Alain. Acquiescence to opacitiy. In: BRETON, Albert; GALEOTTI, Gianluigi; SALMON; Pierre; WINTROBE, Ronald (Orgs.). The economics of transparency politics. New York: Ashgate, 2007. p. 11-35.

SHAW, John. World food security: a history since 1945. New York: Palgrave MacMillan, 2007.

SNYDER, Timonthy. Bloodlands: Europe between Hitler and Stalin. London: The Bodley Head, 2010. THEIEN, Iselin. Food rationing during World War II: a special case of sustainable consumption? Antropology of food. Sept. 2009, 2009.

VEIGA, José Eli. Metamorfoses da política agrícola dos Estados Unidos. São Paulo: Annablume, 1994.

ZOBBE, Henrik. World trade report: the economic and historical foundation of the common agricultural policy in Europe. Unit of Economics Working Papers, n. 12, p. 1-20, 2001.

ZWEINIGER-BARGIELOWSKA, Ina. Introduction. In: ZWEINIGER-BARGIELOWSKA, Ina; DUFFETT, Rachel; DROUARD, Alain (Orgs.). A food and war in twentieth century in Europe. London:

Ashgate, 2011. p. 1-10.

Recebido em março de 2018. Aprovado em dezembro de 2018. 